\title{
La creación de memoria histórica a través de testimonios orales empleando tecnologías de la información y la comunicación
}

\author{
Ana Fuertes ZaPATERo \\ Universidad Complutense de Madrid \\ fuertesdoc@gmail.com
}

\begin{abstract}
Resumen:
Dado el actual nivel de desarrollo de las tecnologías de la información y comunicación (TIC) debemos preguntarnos si cualquier persona es capaz de recoger información a través de testimonios orales, qué hacer con todo el material recopilado hasta ahora y si estos se pueden utilizar para la creación de memoria histórica.

En este artículo se da a conocer a la comunidad científica el proyecto multidisciplinar llevado a cabo por la Universidad Complutense de Madrid sobre los testimonios orales de las Brigadas Internacionales y las aportaciones que de este han surgido.
\end{abstract}

Palabras clave: Memoria histórica; tecnologías de la información y comunicación (TIC); testimonios orales.

\section{The production of historical memory through oral life testimonies by using Information and Communication Technologies (ICT).}

\begin{abstract}
:
In view of the current level of development of Information and Communication Technologies (ICT), we must ask ourselves if any person is capable of gathering information through oral life testimonies, what to do with all the material collected up to the present and if the latter can be used for the production of historical memory.

In this article we want to make known to the science community the cross-disciplinary project perfomed by the Universidad Complutense de Madrid on the oral life testimonies of the International Brigades and the contributions that have appeared throughout its process.
\end{abstract}

Key Words: Historical Memory; Information and Communication Technologies (ICT); Oral Life Testimonies.

\section{Referencia normalizada:}

Fuertes Zapatero, A. (2014): La creación de memoria histórica a través de testimonios orales empleando tecnologías de la información y la comunicación. Historia y Comunicación Social. Vol. 19. Núm. Especial Febrero. Págs. 657-664.

Sumario: 1. Introducción, 2. Metodología, 3. Conclusiones, 4. Bibliografía, 5. Anexo. 


\section{Introducción}

Ya quedó atrás el final de los noventa en España, cuando surgió un movimiento que demandaba la creación de una memoria histórica que aclarase nuestro convulso siglo XX. Este movimiento memorialista comenzó a germinar, en un primer momento, entre las víctimas, sus familiares, ciudadanos y las agrupaciones que fueron creándose alrededor de ellos. Simultáneamente apareció también un cambio dentro de los profesionales de las ciencias sociales y sobre todo, surgió una rama historiográfica, que animaba a historiadores contemporáneos a exhortar y crear una historia que no fuera la que llevaba más de cincuenta años imperando; ya que dentro de dicha disciplina, seguía existiendo una negación y un revisionismo sobre muchos temas. Había llegado el momento de iniciar la constitución de una historia imparcial.

La memoria y la historia recíprocamente se nutren. La memoria es presente, en cambio, la historia pertenece al pasado. Pero lo más importante y relevante para comprender este artículo, es que no debemos confundir memoria histórica con el resto de memorias, ya sean, la oficial, las personales o de colectivos sociales o políticas.

Deberemos referirnos a memoria histórica tal y como dice Cuesta (2008:13)

“aquella que resulta de un arduo trabajo de explicación y comprensión".

Para llevar a cabo todo este trabajo, las ciencias sociales desarrollan esta función y facilitan el tan necesario entendimiento.

En España, la elaboración de la memoria histórica ha sido y sigue siendo un tema muy controvertido y que levanta mucha polémica, aún cuando, La Ley de Memoria Histórica se votó en el Congreso de los Diputados con 304 votos a favor, 18 abstenciones y solamente 3 votos en contra. Dicha Ley se puso en marcha el 27 de diciembre de 2007, como reconocimiento moral a las víctimas de la Guerra Civil y del franquismo. Desde el año 2006 el Ministerio de la Presidencia del Gobierno de España ha concedido a través de concurso público, subvenciones a proyectos de investigación y otras actividades relacionadas con la recuperación de la memoria histórica. Entre estas actividades, destacamos las acciones en las que se recopilasen, conservasen y difundiesen testimonios orales de víctimas directas.

En este contexto, en el año 2012 se llevó a cabo desde la Universidad Complutense de Madrid una investigación denominada: "Tratamiento documental avanzado del archivo audiovisual de los testimonios orales de los Brigadistas Internacionales depositado en el Archivo Histórico Provincial de Albacete".

Esta investigación se llevó a cabo por un equipo de científicos y profesionales compuesto por antropólogos, historiadores, politólogos, comunicadores sociales, documentalistas, etc. Todos ellos pertenecientes a las diferentes ramas de las ciencias sociales. La labor que se pretendía abordar era ambiciosa, ya que se quería dar un paso más en la recogida de los testimonios orales y en el depósito de los materiales audiovisuales en un archivo. El tratamiento se hizo desde una perspectiva multidisci- 
plinar y desde cada una de las diferentes disciplinas se aportaron los conocimientos necesarios para la realización del proyecto que más tarde se explicará.

A parte de los buenos resultados obtenidos en el transcurso de la investigación, se deja una puerta abierta para una futura continuidad de la misma. En base a los resultados derivados de dicho trabajo, el presente artículo ofrece una reflexión sobre las posibilidades que ofrece el uso de las nuevas tecnologías de la información y la comunicación (TIC) para contribuir a la recogida de testimonios orales.

Del mismo modo, se plantean algunas de las dificultades que en relación con la gran cantidad de registros orales y/o audiovisuales se está produciendo derivado de la proliferación masiva del uso de dispositivos multimedia y de la inmediata disponibilidad de ese material. También se recapacita sobre la importancia de crear protocolos de actuación para la recogida, el procesamiento, la reflexión y la sistematización de los testimonios recuperados para que sirvan como base para hacer historia, y más concretamente para la constitución de la memoria histórica.

Lamentablemente, aunque han pasado muy pocos años de la puesta en marcha de la Ley, las ayudas destinadas a tales efectos se han visto congeladas desde el año 2012 .

\section{Metodología}

La cultura democrática de un país pasa porque sus ciudadanos entiendan su propia historia, actualizando y recordando los sucesos acaecidos a lo largo de los años y creciendo conjuntamente como pueblo en valores humanos. Todo ello es lo que aporta una memoria histórica realizada y explicada a la ciudadanía.

Como parte de esta memoria histórica, muy concretamente de un episodio de solidaridad de nuestra Guerra Civil, nació el proyecto de recuperación de la memoria oral de las Brigadas Internacionales.

Mediante financiación del Ministerio de la Presidencia del Gobierno de España se realizó la recogida de dicha memoria de los brigadistas procedentes de Argentina, Bulgaria, Cuba Canadá, México, y la antigua URSS. Las ediciones de las historias orales, divididas en dos proyectos correlativos, permitieron la puesta a disposición de la comunidad científica de una serie de grabaciones audiovisuales de gran valor histórico, sociológico, antropológico y cultural.

Sin embargo, para que toda esta serie adquiriese un verdadero valor para la investigación se hacía necesario un análisis riguroso y exhaustivo de las mismas, en aras a facilitar una correcta y completa explotación de las fuentes documentales. Al mismo tiempo, que redundase en una mayor difusión y conocimiento de las historias de vida de los brigadistas, tanto para la comunidad científica, como para el público en general, ya que su ejemplo permite comprender y actualizar acontecimientos, tal y como se describía anteriormente, requisito imprescindible para tener memoria histórica. 
La investigación a la que alude este artículo, tomó como punto de partida los materiales resultantes los trabajos realizados en 2007 y 2008 pertenecientes a la recuperación de la memoria de los brigadistas internacionales previamente citados.

En el año 2012, la Universidad Complutense de Madrid con la misma financiación pública que permitió la recogida de las historias de vida, concedió a esta institución, una subvención para que continuara las investigaciones anteriormente mencionadas.

Para la realización de esta nueva labor, no sólo se tomó como punto de partida los testimonios recopilados, sino que además se partió de un concienzudo trabajo posterior. Toda la reflexión que en términos teóricos se había realizado y toda la sistematización de la metodología, llevada a cabo en torno al proyecto de recogida de la memoria.

Dicho trabajo, proviene de la investigación predoctoral que realicé para la obtención del DEA denominado: El uso de recursos multimedia en el registro y la investigación de la memoria oral y que también se describe en el artículo: Antón; Alonso \& Fuertes (coords.)(2012). Los testimonios orales en la práctica: revisión crítica sobre el procedimiento (Periodismo y Memoria Histórica. Salamanca: Comunicación social.

La recogida de memoria oral llevada a cabo se hizo a través del método de "historias de vida", por lo que hizo que no sólo las entrevistas se centrasen en los recuerdos de nuestra contienda, sino que los relatos contuviesen los hechos principales de la historia del siglo XX (movimientos migratorios, sociales y políticos, II Guerra Mundial, nuevo orden mundial, etc.). Acrecentándose así el valor del contenido y los campos que necesitaban ser investigados. Por lo tanto, las disciplinas científicas seleccionadas para esta nueva investigación multidisciplinar fueron:

1. Documentación, Biblioteconomía y Archivística.

2. Métodos y técnicas de investigación.

3. Política e Historia Contemporánea. Especialistas en la Guerra Civil española.

4. Sociología y Cambio Social.

5. Comunicación.

La metodología que se llevó a cabo se dividió en tres etapas o fases:

1. La revisión en profundidad de todo el material desde los diferentes campos de conocimiento por los diferentes investigadores multidisciplinares. Para esta etapa las ramas de conocimiento requeridas fueron:

- 1.1. Sociología, Política e Historia, identificando los criterios y variables de estudio útiles y necesarios para el análisis y la investigación de dichas fuentes documentales.

- 1.2. Métodos y técnicas de investigación social, diseñando una sistemática de análisis e investigación que posteriormente podría ser extrapolada a otros proyectos y campos de actividad. 
- 1.3. Ciencias de la Documentación, desarrollando análisis de contenido y diseñando las herramientas más adecuadas para facilitar el acceso y la recuperación de la información.

2. En esta segunda fase los expertos en documentación diseñaron y crearon una aplicación piloto que se encargaría de mostrar y recuperar la información, que en los diferentes análisis anteriores se había recopilado, a través de un motor de búsqueda asociado a una base de datos documental.

3. En la última fase, los expertos en comunicación se encargaron de realizar unas jornadas científicas, no sólo para dar a conocer a la comunidad científica la investigación realizada, sino, para que expertos ajenos a dicho trabajo pero sí vinculados al tema propuesto, validasen y aportasen mejoras que en la recta final del proyecto se pudieran añadir, mejorando así entre todos el resultado.

También se llevó a cabo la edición de un libro en donde se recopiló y explicó la experiencia llevada a cabo en el proyecto que lleva por título Fuertes \& Cadilla (coords.) (2013) Las Brigadas Internacionales. Estudio multidisciplinar sobre los testimonios orales de sus protagonistas. Salamanca: Comunicación social.

Para llevar a cabo estas tres fases metodológicas, se realizó una estructuración del trabajo y se dividieron las tareas de la forma siguiente:

1. Visionado de las grabaciones audiovisuales y transcripción de los relatos orales.

2. Análisis de contenido de los relatos.

3. Análisis documental de los relatos.

4. Diseño y elaboración de una base de datos para albergar los resultados del análisis y permitir la recuperación de la información de la manera más eficiente posible.

5. Diseño y elaboración de una página web con la misma finalidad, susceptible de ser puesta a disposición de la comunidad científica.

6. Organización y celebración de unas jornadas de trabajo, con la participación del equipo de investigación junto con diversos expertos, con el fin de exponer el proyecto y validar sus resultados.

7. Edición y publicación de un libro que recogiese las ponencias y los resultados del proyecto y de su validación.

Mediante el seguimiento de esta metodología, se consiguió cumplir los objetivos, que todo proyecto de investigación propone, cumpliendo así ante el Ministerio.

Como objetivo general estaba la puesta en valor de dichos testimonios y su difusión por medio de un sistema de recuperación documental, ya que son en sí mismos, un patrimonio colectivo de la humanidad. Por consiguiente, el aprovechamiento que se puede hacer de los mismos en muchos ámbitos de las ciencias sociales a partir de 
esta investigación son incalculables, al igual que para el conocimiento de la ciudadanía en general y la creación de nuestra historia y de nuestra memoria histórica. Todo este valor viene refrendado al partir de que la investigación se nutre de fuentes documentales primarias.

Además de este objetivo general, se llevaron a cabo como objetivos específicos todos los nombrados a continuación:

1. Exploración en profundidad del contenido del fondo.

2. Establecimiento de los criterios de análisis que deben tenerse en cuenta para la optimización y el aprovechamiento científico e investigador del fondo archivístico creado en los proyectos anteriores.

3. Diseño de una herramienta específica conforme a los parámetros y criterios de análisis establecidos, para que los investigadores trabajen el contenido del fondo.

4. Creación de una base de datos documental específica, apta para su difusión a través de Internet y accesible a los investigadores interesados por el mismo medio, dotada de un sistema de recuperación de información con motor de búsqueda en el que se tendrán en cuenta metadatos de conservación y preservación digital (premis).

5. Difusión entre la comunidad científica de la existencia del fondo archivístico y del sistema y herramientas de acceso diseñadas para su aprovechamiento, sometiéndolas a su juicio y validación.

\section{Conclusiones}

A modo de conclusión de este artículo y en base a los resultados obtenidos a lo largo de estos años de experiencia en la recogida y tratamiento de la memoria oral a través de las TIC, para la construcción de nuestra memoria histórica podemos aportar algunas reflexiones sobre el trabajo realizado y las posibilidades que existen para investigaciones futuras.

En este siglo que vivimos, la innovación tecnológica se desarrolla muy rápidamente, apenas sin dejarnos asimilar los avances que se producen casi a diario. Estamos ante una revolución en cuanto a capacidad de producción, de transmisión y de poner a disposición del resto del mundo la información generada por nuestros dispositivos multimedia, en cualquier lugar y momento del día. Todo ello, ha hecho que nos sigamos preguntando, si cualquier persona puede erigirse como informante y puede dedicarse a recopilar memoria desde cualquiera de los modernos dispositivos actuales, que permiten grabar y enviar o depositar instantáneamente toda la información recabada. 
¿Cómo hacerlo, quién puede hacerlo (historiador, investigador, ciudadanos...)? ¿y comunicarlo? ¿dónde depositarlo? ¿para qué servirá? son algunas de las preguntas a las cuales tendremos que contestar para la construcción de memoria histórica, la cual, ha sido y sigue siendo uno de nuestros objetos de estudio. Todas estas preguntas no son un tema nuevo de discusión. En muchos congresos internacionales se sigue debatiendo, pero aún no se ha llegado a una solución, a un consenso, que aúne criterios con los que poder trabajar todos en la misma línea.

Desde nuestra humilde, pero enriquecedora vivencia, podemos aportar, que la experiencia con las fuentes orales, sin entrar ya en discusiones sobre los seguidores del positivismo, es un aporte muy válido e interesante; ya que volvemos a situar al ser humano en el centro de la historia. De tal manera, que cumplimos así, con el objetivo de sacar del anonimato a personajes únicos que constituyeron parte de nuestra historia y que a través de sus vivencias podemos, no sólo saber sobre ellos, sino más sobre la situación geopolítica, los movimientos sociales, etc. que nos harán comprender mucho mejor todo lo acontecido en este periodo.

El hecho de proceder toda la información básica de una fuente documental primaria, tanto para las ciencias sociales como para las disciplinas historiográficas, ha permitido que el trabajo conjunto de las diferentes ciencias en un proyecto multidisciplinar tenga como resultado final un campo mucho más amplio y que además, se pueda en un futuro, retomar, tanto por separado como nuevamente uniendo fuerzas, para que se hagan muchas más investigaciones que aporten a los profesionales y la ciudadanía nuevos resultados esclarecedores, de una etapa de nuestra historia muy controvertida.

En referencia a las TIC, la mayor ventaja de recoger historias orales con soportes multimedia, es que podemos aprovechar todo lo que a través del lenguaje corporal nos aporta el entrevistado. Se puede obtener mucha más información de la que el mero discurso contiene. El entrevistado, a través de su cuerpo y sus gestos, sus silencios o entonaciones, nos ofrece un mundo de posibilidades para seguir profundizando en su historia. Con este recurso se pueden detectar contradicciones, mentiras, silencios forzosos al no querer contar algo, sentimientos reales, emociones, ironía, etc. Muchas de estas percepciones se pierden al trabajar sólo con transcripciones o con grabaciones de voz. Además la grabación multimedia nos permite sacar del anonimato a los personajes a los que la historia, normalmente, no da voz. La historia de todos aquellos que no siendo famosos ni quizás logrando grandes hazañas, entre todos conformaron uno de los grandes episodios de solidaridad que la humanidad ha conocido.

En España se da el caso, tal y como se apunta en la introducción, de que no son las instituciones públicas sino un conjunto de la ciudadanía la que da empuje para la creación de memoria histórica. La mayor parte de todos los proyectos que se han hecho tanto con subvenciones del Ministerio de la Presidencia, como por parte de otros organismos públicos o privados, se han desarrollado, sobre todo de forma voluntaria. Todo este trabajo se ha hecho desde asociaciones y colectivos que, con mucho 
esfuerzo, han recogido documentación, grabado testimonios, escrito libros, realizado documentales, homenajeado a las víctimas, buscado en archivos, exhumado fosas, erigido monumentos, etc.

Desde el año 2010, en las dos últimas convocatorias de subvenciones públicas del Ministerio, la universidad entró a formar parte aportando profesionales y recursos que dieron un carácter científico a los proyectos. Pero sería muy injusto que el trabajo que se ha realizado anteriormente a dicha entrada de la universidad, se menospreciase por la creencia de que estos trabajos realizados no tuvieran unos criterios metodológicos ni científicos. Muchos de esos trabajos se han regido por unos razonamientos y normas que los hacen muy válidos. Así pues, es una gran oportunidad para que ahora la comunidad científica aproveche toda esta labor y la continúe.

El proyecto que la Universidad Complutense de Madrid llevó a cabo, y que se pone aquí en conocimiento, debe de servir como ejemplo de lo explicado. Se creó un grupo de investigación multidisciplinar que aprovechó toda la labor realizada anteriormente con los materiales recogidos en años anteriores para dar unos aportes científicos, ampliar la investigación y para que la información recabada no se quedase depositada sin más en un archivo y así sirviese para posibles trabajos posteriores. Pero sobre todo para dar a conocer esta parte de nuestra historia.

Al hilo de lo explicado, nos asalta otra pregunta para la reflexión, es ¿dónde se debería guardar todo lo recopilado? ¿Dónde acudir para saber todo lo que se ha hecho durante estos años? Diferentes archivos, grandes y pequeños, repositorios comerciales o gestionados por manos privadas. Debe de existir un código deontológico que garantice la correcta conservación y sobre todo, el acceso.

Pero para todo el material que se realiza no a través de subvenciones públicas, sino a través de las TIC por cualquier colectivo o persona interesada, y que en poco tiempo se puede poner en los repositorios de moda, deberíamos preguntarnos ¿qué pasará en un futuro? ¿qué pasará cuando se cierren o se deniegue la posibilidad de acceso a estos repositorios? ¿y todo lo referente a los derechos de propiedad intelectual? Todo esto debe hacernos reflexionar para llegar a consensos en donde todos respetemos y sigamos los criterios y pautas establecidos.

Aún son muchas las preguntas por resolver y mucho el trabajo por hacer. Es el momento en el que los científicos deben recoger este material que durante los últimos años se ha recopilado, todo un legado, y trabajemos con él para que la ciudadanía llegue a conocer y comprender su memoria histórica.

\section{Bibliografía}

ANTÓN; Alonso \& FUERTES. Coordinadoras. (2013) Periodismo y Memoria Histórica. La contribución del periodismo en la recuperación de la Memoria Histórica a partir de testimonios orales. Salamanca: Comunicación social. 